\title{
A COMPREENSÃO DOS PROFESSORES SOBRE AS DIFI- CULDADES NO PROCESSO DE ESCOLARIZAÇÃO: ANÁLISE COM PRESSUPOSTOS VIGOTSKIANOS*
}

TEACHERS' UNDERSTANDING ON DIFFICULTIES IN THE SCHOOLING PROCESS: ANALYSIS WITH VYGOTSKIAN ASSUMPTIONS

EL ENTENDIMIENTO DE LOS PROFESORES SOBRE LAS DIFICULTADES EN EL
PROCESO DE ESCOLARIZACIÓN: ANÁLISIS CON PRESUPUESTOS VIGOTSKIANOS

\author{
Marilda Gonçalves Dias Facci \\ Pós-doutora em Psicologia Escolar e do Desenvolvimento Humano \\ pelo Instituto de Psicologia da USP \\ marildafacci@gmail.com \\ Nilza Sanches Tessaro Leonardo \\ Doutora em Psicologia pela PUC/Campinas \\ milribeiro@uem.br \\ Maria Júlia Lemes Ribeiro \\ Doutora em Educação pela Universidade de São Paulo \\ nstessaro@uem.br
}

RESUMO: Atualmente, temos um grande contingente de crianças frequentando a escola, porém muitos alunos não têm se apropriado dos conhecimentos curriculares, fato que é objeto de estudos no âmbito da Educação e da Psicologia Escolar e Educacional. Nesse contexto, nosso objetivo é apresentar a compreensão de professores sobre as dificuldades encontradas no processo de escolarização e o relato que fazem sobre o enfrentamento dessas dificuldades em uma cidade do Norte do Paraná. Para tanto, inicialmente, faremos uma discussão sobre o fracasso escolar; na sequência, apresentaremos alguns pressupostos do processo ensino-aprendizagem com fundamentos na Psicologia Histórico-Cultural e, finalmente, apresentaremos dados de uma pesquisa sobre as queixas escolares realizada com trinta professores das séries iniciais do Ensino Fundamental de cinco escolas. Nossa conclusão foi que uma visão culpabilizante e individualizadora continua explicando as dificuldades no processo de escolarização e que os alunos vivem em uma sociedade excludente, a qual não socializa os bens materiais e culturais de forma igualitária. Também, concluímos ser necessário propor mediações diferenciadas, para que todos os estudantes tenham acesso ao conhecimento.

PALAVRAS-CHAVE: Queixas escolares. Educação. Psicologia escolar e educacional. Psicologia histórico-cultural.

ABSTRACT: Nowadays, a great number of children are going to school; however there is a general complaint that many of those children are not internalizing curriculum knowledge. This fact has actually been focused in studies by Education and by School and Educational Psychology. This paper focus on teachers' understanding about difficulties involved in the schooling process and the reporting made about facing them in a town in the northern region of the state of Paraná, Brazil. A discussion of school failure will be held, followed by some presuppositions of the teaching-learning process foregrounded on Historical and Cultural Psychology. Data from a research on school complaints with thirty teachers of the first forms of the Primary School from five schools will be given. A guilt-ridden and individualized point of view is still rife to explain the difficulties in the schooling process. Further, data reveal that students live in an excluding society which does not socialize equally material and cultural goods. Differentiated mediations are required so that knowledge may be accessible to all students.

KEYWORDS: School complaints. Education. School and educational psycology. Historical and cultural psychology.

\footnotetext{
* Artigo recebido em fevereiro de 2014

Aprovado em março de 2014
} 


\section{artigo}

RESUMEN: Actualmente hay un gran contingente de niños frecuentando la escuela, sin embargo muchos alumnos no se han apropiado de los conocimientos curriculares, hecho éste que es objeto de estudios en el ámbito de la Educación y de la Psicología Escolar y Educacional. En ese contexto, nuestro objetivo es presentar el entendimiento de profesores sobre las dificultades encontradas en el proceso de escolarización y el relato que se hacen sobre el enfrentamiento de ellas en una ciudad del Norte de Paraná. Para tanto, inicialmente haremos una discusión sobre el fracaso escolar; en la secuencia presentaremos algunos presupuestos del proceso enseñanza-aprendizaje, con fundamentos en la Psicología Histórico-Cultural; y, finalmente, presentaremos datos de una investigación sobre las quejas escolares realizada con treinta profesores de las series iniciales de la Enseñanza Fundamental de cinco escuelas. Nuestra conclusión fue que una visión de culpabilidad e individualizadora sigue explicando las dificultades en el proceso de escolarización, y que los alumnos viven en una sociedad excluyente, la cual no socializa los bienes materiales y culturales de forma igualitaria. También concluimos ser necesario proponer mediaciones diferenciadas, para que todos los estudiantes tengan acceso al conocimiento.

PALABRAS CLAVE: . Quejas escolares. Educación. Psicología escolar y educacional. Psicología histórico-cultural. 


\section{1 | Introdução}

Atualmente, temos um grande contingente de crianças frequentando a escola, pois de acordo com o censo escolar de 2012, foram efetuadas 50.545.05 matrículas na Educação Básica, nas esferas estadual e municipal (INEP, 2013). Não obstante, o aumento do número de matrículas (98,3\% matriculados em 2011$)$ e o fato de "quase todas" as crianças de seis a catorze anos estarem nas escolas (BRASIL, 2013), isso não garante a aprendizagem e o desenvolvimento, nem se traduze em oportunidade igual de escolarização para todos ou de inserção e participação social.

Mesmo com a implantação de reformas educacionais e de pactos internacionais, quando se trata de avaliar o indicativo de qualidade da educação, tendo-se como referência os índices de alunos que completam a primeira etapa do Ensino Fundamental, dentre os 129 países avaliados, o Brasil ocupa a 93a posição (dados de 2005). Em 2005, apenas $80,5 \%$ dos alunos que iniciaram a $1^{\underline{a}}$ série do Ensino Fundamental chegaram até a $5^{\mathrm{a}}$ série, enquanto, em 2001, o percentual foi de $84,5 \%$. Este percentual cai quase pela metade $(46,9 \%)$ em se tratando de jovens e adultos que chegam ao Ensino Médio (UNESCO, 2008).

Temos, ainda, um percentual de $15,2 \%$ de crianças de oito anos de idade não alfabetizadas, e a estimativa de que $51,4 \%$ dos alunos de escolas públicas que concluíram o $3^{\circ}$ ano do Ensino Fundamental não adquiriram os conhecimentos esperados para essa etapa, como indica o índice de leitura da Avaliação Brasileira do Ciclo de Alfabetização-Prova ABC. (ANUÁRIO BRASILEIRO DA EDUCAÇÃO BÁSICA, 2012).

Os dados oficiais e a realidade encontrada nas salas de aula revelam que muitas crianças estão sujeitas a um processo histórico de marginalização, o que constitui uma das mazelas educacionais, causando as queixas escolares e as dificuldades identificadas pelos educadores no que se refere ao rendimento escolar ou ao comportamento dos alunos, fatores que interferem negativamente no processo ensino-aprendizagem, determinando o fracasso escolar. Tais dificuldades geralmente resultam no encaminhamento destes alunos para atendimento pedagógico, psicológico, médico e outros que possam sanar tal problemática e/ou intervir no diagnóstico/ prognóstico de fracasso escolar, aspectos sobre os quais trataremos nesse artigo. Nosso objetivo é apresentar a compreensão de professores sobre as dificuldades encontradas no processo de escolarização e o relato que fazem sobre como as enfrentam em uma cidade do Norte do Paraná. Para tanto, inicialmente faremos uma discussão sobre o fracasso escolar; na sequência, apresentaremos alguns pressupostos do processo ensino-aprendizagem com fundamentos na Psicologia Histórico-Cultural e, finalmente, apresentaremos dados de uma pesquisa realizada com professores acerca das queixas escolares.

É importante destacar que a pesquisa relatada, neste artigo, está vinculada a um projeto maior denominado, "Desenvolvimento humano, escolarização da criança e do adolescente e processos institucionais: contribuições da psicologia", desenvolvido no Programa Nacional de Cooperação Acadêmica: ação novas fronteiras (PROCAD-NF), do qual participam o Programa de Pós-Graduação em Psicologia da Universidade Estadual de Maringá, o Programa de Mestrado Acadêmico em Psicologia da Universidade Federal de Rondônia e o Programa de Pós-Graduação em Psicologia Escolar e do Desenvolvimento Humano da Universidade de São Paulo. Informamos, ainda, que o presente estudo diz respeito a um dos eixos - "Queixas escolares na perspectiva de professores" - contemplados no respectivo projeto.

\section{2 | 0 fracasso escolar}

Ao longo da história, foram sendo construídas explicações para o fracasso das escolas, no sentido de compreender e desmistificar essas concepções. Patto (1990), ao empreender a busca das raízes históricas, revela, em seu estudo, "A produção do fracasso escolar: histórias de sub- 
missão e rebeldia", que os argumentos que justificam as dificuldades de aprendizagem são dados como inerentes às crianças de classes populares, de modo que, ideologicamente, o pobre e a pobreza são responsabilizados pela conjuntura de problemas escolares e por sua ineficiência.

Podemos dizer que a sociedade capitalista gera o fracasso das camadas populares e que a Psicologia, ciência que surgiu para servir aos interesses da classe burguesa, tem contribuído para isso. Segundo Patto (1984), a Psicologia garantiu o seu status de ciência na Europa, na segunda metade do século XIX, quando as indústrias se encontravam em ascensão e foi sendo constituída para atender à necessidade de "selecionar, orientar, adaptar e racionalizar, visando, em última instância, a um aumento da produtividade" (PATTO, 1984, p.87). Isso ocorreu especialmente na Psicologia do Trabalho e na Psicologia Escolar, esta última atrelada às origens da psicologia científica. Segundo Patto (1984, p. 96), "a psicologia nasce com a marca de uma demanda: a de prover conceitos e instrumentos 'científicos' de medida que garantam a adaptação dos indivíduos à nova ordem social”. Desta forma, o principal trabalho da Psicologia na escola é adaptar, seja pela seleção, seja pela orientação. Assim, segundo Patto (1984, p.99):

[...] A primeira função desempenhada pelos psicólogos junto aos sistemas de ensino, seja na França, seja nos Estados Unidos, seja no Brasil, seja nos demais países que se valeram dos recursos fornecidos pela psicologia para encaminhar seus projetos educacionais, foi a de medir habilidades e classificar crianças quanto à capacidade de aprender e de progredir pelos vários graus escolares.

Patto (1990) mostra que, no início do século XIX (e muitas vezes até hoje), as ciências humanas e sociais, ao invés de buscarem considerar e desvendar as contradições do capitalismo, a ideologia dominante e as desigualdades sociais, colocavam-se à disposição de mantê-las, desenvolvendo teorias que justificavam o abismo social para encobrir as mazelas de nossa sociedade. De acordo com a autora, ao não comportar a complexidade da vida humana, os conhecimentos produzidos na época (e comumente os produzidos atualmente) sintetizam teorias derivadas e construídas na forma de mitos, a fim de explicar a não aprendizagem dos alunos das escolas públicas.

Uma das teorias discutidas por Patto (1990) é a teoria racista que teve intensa divulgação nos primeiros anos do século XIX, com a defesa da existência de raças distintas, voltando-se contra o ideário cristão de que todos os homens foram criados à imagem e semelhança de Deus. Tal teoria defendia a necessidade de hierarquia social, distinguindo e selecionando os mais aptos, segundo os princípios evolucionistas de Darwin, devendo ser oferecido ensino diferenciado aos alunos em razão de sua potencialidade e aptidão. Nesse campo, os testes psicológicos tiveram espaço para medir e consolidar os talentos individuais, explicando o fracasso escolar como distúrbio do desenvolvimento psicológico.

Segundo a autora, na década de 1960, surgiram, nos Estados Unidos, as teorias do déficit e da carência cultural para explicar o fracasso escolar e o insucesso escolar dos mais pobres, sustentando que o fato de não avançar as crianças na escola era resultante de um ambiente sociocultural desfavorável. A causa principal do fracasso era o aluno ser de baixa renda, cabendo à escola adequá-lo, enquanto os aspectos intraescolares eram pouco considerados; mas, quando enfocada a diferença cultural, a escola era responsabilizada pelo fracasso, por sua inadequação à clientela. Desta maneira, era discutido o fato de a escola exercer a dominação cultural, com a leitura de uma imposição dos valores da classe bem-sucedida à classe malsucedida. A cultura dos mais pobres era considerada inadequada à sua ascensão social, cabendo à educação, especificamente ao professor, buscar as formas mais adequadas para aculturar seus alunos, visando à sua ascensão social.

Para a autora, tais alegações são derivadas de "mitos" que explicavam à época - e, ainda, se 
encontram disseminados na atualidade - as diferenças individuais e sociais, isentando a desigualdade social inerente ao sistema capitalista e colocando a pobreza como fator determinante. A Teoria da Carência Cultural apresentava como causas do fracasso escolar baixo QI, imaturidade, carência afetiva, falta de acompanhamento dos pais, diferença de linguagem, desnutrição e outras, mas, no âmago da questão, colocava sobre os indivíduos a culpa de não aprender.

Constatamos, assim, que, ao longo da história, várias explicações teóricas têm sido construídas pelo viés da culpabilização do indivíduo, patologizando os problemas escolares e defendendo a existência de distúrbios de aprendizagem nos alunos com problemas de escolarização. Souza (2000) alerta que, antes de se considerar a hipótese de distúrbio de aprendizagem, devem ser levantadas todas as informações da escola onde a queixa é produzida.

Muitos são os motivos apontados pelos educadores como responsáveis pelas queixas escolares, sendo o mais polêmico deles o "aluno-problema", apresentado como portador de "distúrbios psicopedagógicos", que podem ser de ordem cognitiva ou comportamental. Dessa forma, é isentado o profissional da educação da responsabilidade e da necessidade de uma maior reflexão sobre sua prática, uma vez que não se pode fazer nada com alunos-problema.

Garrido e Moysés (2010, p. 150), contribuindo com a reflexão, afirmam:

Nas últimas duas décadas vem sendo cada vez mais aceita no Brasil a ideia de que as dificuldades escolares de uma criança são causadas por problemas de ordem médica. Essa certeza abre espaço para profissionais da saúde, exames, rótulos, diagnósticos, remédios, todos voltados a legitimá-la e a transformar crianças em crianças-problema ou anormais.

Meira (2011) expõe que, para explicar o fracasso escolar, a Psicologia também vem apresentando diversos argumentos pretensamente científicos, todos eles com centralidade no indivíduo, tais como: disfunções orgânicas, traços de personalidade, capacidade intelectual, habilidades e competências perceptivo-motoras, problemas emocionais, conflitos familiares e outros.

Para Facci (2007), culpar apenas o indivíduo pelo não aprendizado escolar resulta numa explicação simplista e ideológica, pois nisto estão imbricados os pressupostos neoliberais, que retiram os fatores sociais envolvidos no contexto do fracasso escolar e naturalizam essas questões.

Falamos do fracasso, mas como pensar no desenvolvimento das potencialidades dos alunos? Sobre isso trataremos no próximo item, tomando como referência os pressupostos da Psicologia Histórico-Cultural.

\section{3 | 0 processso ensino-aprendizagem à luz da psicologia histórico-cultural}

A Psicologia Histórico-Cultural foi elaborada, inicialmente, por L. S. Vigotski ${ }^{1}$ (1896-1934) e depois continuada por A. N. Leontiev (1903-1979), A.R. Luria (1902-1977) e outros estudiosos russos. Essa teoria tem como base metodológica o materialismo histórico-dialético. Nesta perspectiva, o historicismo marca o desenvolvimento humano e o homem é compreendido como síntese das relações sociais, ou seja, o psiquismo está atrelado às condições materiais, à forma como os homens, por meio do trabalho, foram transformando a realidade e, consequentemente, transformando-se a si próprios..

Leontiev (1978) afirma que o homem aprende a ser homem mediante a apropriação do conhecimento, no processo educativo. Assim, é por meio das mediações realizadas pelos homens no processo histórico que o desenvolvimento ocorre em nível ontogenético. O homem se apropria da cultura e supera, assim, o desenvolvimento biológico. Assim, o aprendizado é condição

\footnotetext{
${ }^{1}$ Nas leituras realizadas constatamos que Vigotski é grafado de diferentes formas. Adotaremos essa grafia, salvo em caso de referência e citação.
} 
imprescindível para o desenvolvimento do psiquismo humano. Neste sentido, o aluno que apresenta queixas escolares necessita de mediações diferenciadas para se apropriar da linguagem escrita, da leitura e da matemática.

Vigotski (2000) entende que são complexas as relações entre aprendizagem e desenvolvimento. O indivíduo desenvolve-se, em parte, graças à maturação do organismo individual, enquanto pertencente à espécie humana, mas é o aprendizado que provoca a interiorização da função psíquica; os conhecimentos curriculares, ensinados pelo professor, provocam o desenvolvimento das funções psicológicas superiores, como a memória lógica, a abstração, a atenção concentrada, a criatividade e outras.

Vigotski (2000) entende que existem dois níveis de desenvolvimento:

a) o nível de desenvolvimento real ou efetivo, que constitui as funções psicológicas já efetivadas, formadas e amadurecidas pelo indivíduo, como resultado de ciclos de desenvolvimento já completados;

b) o nível de desenvolvimento próximo, que se define como aquelas funções que estão em vias de amadurecer, as quais podem ser identificadas através da solução de tarefas, com o auxílio de adultos e/ou outras crianças mais experientes. Enquanto aquele nível caracteriza o desenvolvimento mental retrospectivamente, este o caracteriza prospectivamente.

O processo educativo, segundo o autor russo, deve atuar no nível de desenvolvimento próximo, naquilo que ainda não foi efetivado. "Ensinar uma criança o que ela não é capaz de aprender é tão estéril quanto ensiná-la a fazer o que ela já faz sozinha" (VIGOTSKI, 2000, p. 337). Assim, na atividade realizada com alunos com queixas escolares, o professor tem que ter clareza dos conhecimentos que já estão efetivados, que estão internalizados, assim como dos conhecimentos que estão no nível de desenvolvimento próximo e deve propor atividades que hoje o aluno realize com ajuda e amanhã possa realizar sozinho. Existe uma dependência recíproca, complexa e dinâmica entre esses dois processos.

A característica essencial da aprendizagem é que estimula na criança, conforme Vigotski (2000), um conjunto de processos internos que, com a mediação, Ihe possibilitarão apropriar-se do conhecimento, o que, por sua vez, contribuirá para que ela internalize também o que foi ensinado. Para que ocorra a apropriação dos conteúdos pedagógicos, é necessário que estes sejam internalizados. O processo de apropriação ocorrerá sempre com a passagem do nível interpsicológico para o nível intrapsicológico.

Quando chega à escola, a criança tem que aprender, entre outras coisas, a linguagem escrita, aquisição que significa, para a criança, apropriar-se de um sistema de signos extremamente complexo, pois, como afirma Vigotski (2000), a linguagem escrita é arbitrária, exige tomada de consciência e se apoia na linguagem verbal. Para aprender a escrever, a criança tem que tomar consciência da estrutura fonética da palavra, desmembrá-la e reproduzi-la voluntariamente em signos. A distinção entre a linguagem escrita e a oral deve-se à separação entre, por um lado, os níveis de desenvolvimento da atividade espontânea, involuntária e não consciente, e, por outro, a atividade abstrata, voluntária e consciente.

Aprender a escrever e a fazer as operações da matemática, por exemplo, é um processo que ativa a formação das funções psíquicas superiores, provocando mudanças radicais nessas funções. A aprendizagem se adianta ao desenvolvimento e provoca o seu avanço. Cada matéria escolar tem uma relação própria com o curso de desenvolvimento e a criança, no processo educativo, assimila determinados conteúdos antes de aprender a utilizá-los consciente e voluntariamente. Neste processo, o professor precisa empreender ações que promovam essa tomada de consciência, para que os alunos formem os conceitos. 
A formação dos conceitos científicos não é uma atividade passiva, ao contrário, é uma atividade intensa e orientada para resolver tarefas cognitivas. Ela inclui planejamento, solução de problemas, a formulação e demonstração de hipóteses e a busca de comprovação de significados. Assim, para Petroviski (1985), a escola deveria ter como objetivo ensinar aos alunos as atividades mentais necessárias para a apropriação do conhecimento. Isso significa que o professor deveria tomar consciência de que, ao ensinar subtração, por exemplo, está ensinando a criança a pensar, está provocando o desenvolvimento da abstração e de outras funções psicológicas.

Davidov e Márkova (1987) corroboram essas ideias e compreendem que, desde o momento que a criança entra na escola, deveria ser preparada para a atividade de estudo. A atividade principal de estudo, segundo Elkonin (1987), é a forma como, nos primeiros anos de escolarização (no nosso caso, no Ensino Fundamental), o aluno se relaciona com a realidade. É por meio desta atividade que, na apropriação dos conteúdos curriculares, o aluno vai tomando consciência da realidade. Davidov e Márkova (1987) entendem que, já nos primeiros anos escolares, as crianças devem ter um indispensável desenvolvimento psíquico e uma boa capacidade para estudar. A escola, para esses estudiosos, deve investir nesses aspectos, pois o fundamento psicológico é fundamental para assegurar a assimilação eficaz dos conhecimentos da ciência e da cultura, nos graus médio e superior. É necessário, desde o primeiro grau, propiciar o ensino do pensamento abstrato e teórico. Quanto aos alunos que, ainda, não se apropriaram dos conhecimentos científicos, podemos afirmar que eles estão, de certa forma, encontrando obstáculos para o pleno desenvolvimento psicológico.

As atividades pedagógicas precisam ser sistematizadas e organizadas pelo professor, com a finalidade de conduzir o aluno à apropriação dos conceitos científicos. O aprendizado não ocorre de forma espontânea, ao contrário, como afirma Saviani (2003), exige intencionalidade, para que aquilo que a humanidade produziu seja apropriado individualmente pelo aluno, fazendo parte da sua segunda natureza. A mediação do professor pode levar os alunos a assimilar os conteúdos, para que possam se desenvolver, apropriando-se da experiência histórico-social. O professor não tem um papel secundário, ele dirige a prática pedagógica, conforme relata Facci (2004). Com sua intervenção, ele pode contribuir para que o aluno aprenda e assim se desenvolva. Como afirma Vigotski (2000), é a aprendizagem que "arrasta" para o desenvolvimento.

O que é necessário ressaltar em relação às queixas escolares é que, na perspectiva da Psicologia Histórico-Cultural, o trabalho pedagógico deve proporcionar ao aluno possibilidades de acesso ao conhecimento, investindo nas suas potencialidades e não nas suas dificuldades, nos brotos e não nos frutos do desenvolvimento, conforme Vygotski (1997).

A seguir, apresentaremos os resultados da pesquisa realizada com professores.

\section{3 | Metodologia}

\section{1 | Caracterização das participantes}

Fizeram parte da pesquisa cinco escolas de ensino básico da rede pública de uma cidade do Norte do Paraná, das quais três se destacavam por apresentarem o maior índice na avaliação do IDEB e duas o menor. Dessas escolas, participaram trinta professores das séries iniciais do Ensino Fundamental, a saber: nove professores do primeiro ano, dez do segundo ano, cinco do terceiro ano e seis do quarto ano. Todos os participantes eram do sexo feminino, com idades entre 28 e 57 anos. Quanto ao grau de escolaridade, todas as educadoras tinham formação superior, sendo que $70 \%$ eram graduadas em Pedagogia e as restantes $30 \%$ detinham outras graduações, como Letras e Normal Superior. Além disso, 73\% delas haviam cursado, no mínimo, uma especialização. O tempo de experiência profissional variou de 2 a 31 anos de docência.. 


\section{2 | Instrumento}

O instrumento utilizado para coletar as informações foi a entrevista semiestruturada, composta de sete questões que objetivavam caracterizar a população participante: idade, sexo, formação, tempo de docência, escola em que trabalha, tempo na escola, horas semanais de trabalho.

Outras seis questões abordavam temas referentes à queixa escolar: queixas escolares (problemas de indisciplina e/ou dificuldades de aprendizagem) identificadas em sala de aula; formas de identificação dos estudantes com queixa escolar; trabalhos de apoio oferecidos pelos professores aos estudantes com queixa escolar; encaminhamentos da escola para os estudantes identificados com queixa escolar; relato de experiências bem sucedidas para o enfrentamento das dificuldades no processo de escolarização; tipos de medicamentos utilizados pelos estudantes e tipos de distúrbios de aprendizagem identificados em classe e o número de estudantes.

Foi utilizado gravador para o registro dos dados e, em apenas dois casos, a gravação não foi permitida.

\section{3 | Procedimentos}

Para o desenvolvimento da investigação, realizamos uma busca nos indicadores do IDEB do ano de 2009, filtrando apenas escolas municipais de uma cidade do Norte do Paraná. A partir disso, estabelecemos contato com a Secretaria Municipal de Educação para obter autorização para realizar a pesquisa. A partir da autorização, ocorreu o contato com as escolas para agendamento de uma reunião com os responsáveis pela direção e a equipe pedagógica, para apresentar a temática e o objetivo da pesquisa, definir o número de participantes, o local e o tempo necessário para a sua realização. As cinco escolas contatadas aceitaram e autorizaram a participação na pesquisa.

Após o parecer favorável do comitê de ética para pesquisas envolvendo seres humanos, entramos novamente em contato com as escolas para marcar o horário para a realização das entrevistas com as participantes. As entrevistas foram realizadas nas dependências das escolas pesquisadas, em geral, nas salas dos professores ou na biblioteca.

O tempo de duração das entrevistas variou, aproximadamente, de quinze a trinta minutos e os dados obtidos foram transcritos, trabalhados e analisados de modo a garantir o anonimato, 0 sigilo e a privacidade sobre a identidade dos entrevistados, bem como das escolas pesquisadas.

\section{4 | Resultados e discussão}

Os dados obtidos nas entrevistas foram organizados de forma a serem identificados os temas e as respostas que os compõem. A seguir, apresentamos as informações, esclarecendo que as porcentagens foram calculadas a partir do total de respostas fornecidas pelas participantes, e não pelo número das participantes. Tomando como referência o discurso das professoras, as respostas foram agrupadas de acordo com a classificação de maior e menor IDEB, as quais estão disponibilizadas em duas colunas nas tabelas. Reunimos as respostas em categorias que foram formuladas pelas pesquisadoras a partir de suas análises. Vale considerar que, quando mencionamos que o número de respostas foi 0,0 , isso significa inexistência de respostas.

Com base nos dados apresentados referentes às queixas identificadas pelas professoras em sala de aula (tabela 1), vemos que, nas duas escolas, a indisciplina é a mais mencionada, ficando com uma frequência em torno de $21 \%$. Alunos com dificuldades na leitura e na escrita ocupam a segunda posição nas duas escolas. Na escola de menor IDEB, as professoras citam que identificam também alunos com TDAH (15,8\%). Em suas respostas, as professoras também citaram a falta de concentração e de interesse pela leitura. 
Tabela 1 - Queixas escolares identificadas em sala de aula

\begin{tabular}{l|l|l}
\hline \multicolumn{1}{c|}{ CATEGORIAS } & $\begin{array}{c}\text { Escolas de } \\
\text { Menor DEB }\end{array}$ & $\begin{array}{c}\text { Escolas de } \\
\text { Maior DEB }\end{array}$ \\
\hline O aluno inquieto, indisciplinado & 21,0 & 31,4 \\
\hline O aluno que apresenta falta de concentração & 0,0 & 7,8 \\
\hline O aluno desinteressado & 0,0 & 7,8 \\
\hline O aluno com dificuldade de leitura e escrita & 15,8 & 9,8 \\
\hline O aluno com TDAH & 15,8 & 3,9 \\
\hline O aluno que não consegue assimilar o conteúdo & 0,0 & 3,9 \\
\hline $\begin{array}{l}\text { O aluno que não recebe atendimento médico e } \\
\text { medicação adequada }\end{array}$ & 0,0 & 5,9 \\
\hline
\end{tabular}

Fonte: Elaborado pelos autoras.

As respostas, na sua maioria, indicaram a indisciplina como a queixa mais presente $-31,4 \%$ na escola de maior IDEB e $21,0 \%$ de menor IDEB. Problemas de comportamento ainda continuam sendo considerados como dificuldade no processo de escolarização, levando a questionar até que ponto, como afirma Leontiev (1978), os alunos estão motivados para aprender. Vigotski (2001), por volta de 1926, já afirmava que o interesse dos alunos em aprender é fundamental na apropriação do conhecimento.

A identificação das queixas escolares pelas professoras, como é o caso do TDAH, do aluno inquieto, daquele que apresenta falta de concentração, denota a necessidade de entendimento acerca das funções psicológicas superiores, como atenção, por exemplo. Muitas vezes, a compreensão dessas questões remete a aspectos biológicos, o que vai (à) na contramão do que propõem Vygotsky e Luria (1996), os quais deixam claro que as funções psicológicas superiores se desenvolvem a partir das mediações realizadas na coletividade. Vigotski (2000) afirma que, quando as crianças estão iniciando o processo de escolarização e a aprendizagem da escrita, é a apropriação dos signos que contribuirá para o seu desenvolvimento cognitivo, pois a aprendizagem provoca o desenvolvimento. É importante ressaltar que a maioria das respostas obtidas referiu-se a aspectos de ordem biológica e comportamental que interferem no aprendizado do aluno, caracterizando a queixa escolar como fenômeno individualizado. Estes dados reiteram o entendimento de queixas escolares pelos professores que diz respeito, em sua maioria, aos aspectos centrados no indivíduo.

Percebemos, em muitas falas das professoras, que continuam explicando as dificuldades sem considerar o contexto histórico-social que as produzem, aspecto já discutido e rejeitado por Patto (1990). Como afirma Souza (2000), a compreensão das queixas escolares ultrapassa o âmbito individual, devendo ser expandida para a análise das relações institucionais e históricas que, continuadamente, vêm contribuindo para que um elevado número de alunos continue sem se apropriar dos conteúdos curriculares, conforme explicitamos no início deste artigo.

Identificadas essas queixas, quais são os encaminhamentos que fazem as professoras? Nas escolas investigadas, elas citam que buscam oferecer atendimento pedagógico individualizado e utilizam metodologia e recursos diferenciados, conforme consta na tabela 2 . Tal prática é muito importante, pois possibilita aos professores identificar aqueles conhecimentos que estão no nível de desenvolvimento próximo dos alunos e, assim, eles podem utilizar recursos mediadores diferenciados capazes de contribuir para a aprendizagem dos alunos. É importante observar que $85 \%$ das escolas de menor IDEB citam que procuram utilizar trabalhos diferenciados, talvez 
justamente por causa do IDEB da escola. Sabemos que ter um baixo IDEB causa muita preocupação e, geralmente, a própria Secretaria da Educação se mobiliza para apoiar a escola na superação desses índices.

Um projeto interessante realizado em uma das escolas de menor IDEB, o projeto Maleta Viajante, incentiva os alunos a lerem e a relatarem o que leram. Outro projeto é o trabalho em duplas ou grupos, em que a criança que tenha entendido melhor o conteúdo ajuda as demais do grupo, como exemplifica a fala de uma professora: "Eu consegui que eles avançassem trabalhando em dupla, um ajudando o outro. Em dupla, em trio e os casos que mais precisam junto comigo". Aqui é importante retomar os escritos de Vigotski (2000) quando afirma que a criança aprende com o adulto mais experiente - o professor - ou com as crianças mais velhas, as quais geralmente dominam melhor os conteúdos.

Tabela 2 - Encaminhamentos oferecidos pelos professores aos estudantes com queixa escolar

\begin{tabular}{l|c|c}
\hline \multicolumn{1}{c|}{ CATEGORIAS } & $\begin{array}{c}\text { Escolas de } \\
\text { Menor IDEB }\end{array}$ & $\begin{array}{c}\text { Escolas de } \\
\text { Maior } \\
\text { IEB }\end{array}$ \\
\hline $\begin{array}{l}\text { A professora busca oferecer um atendimento } \\
\text { pedagógico individualizado }\end{array}$ & 50,0 & 45,8 \\
\hline A professora busca colocar o aluno mais próximo a ela & 0 & 16,7 \\
\hline $\begin{array}{l}\text { A professora utiliza recursos, avaliações e } \\
\text { metodologias pedagógicas diferenciadas em sala de } \\
\text { aula }\end{array}$ & 85,0 & 29,2 \\
\hline $\begin{array}{l}\text { Faz o encaminhamento do aluno para o apoio } \\
\text { pedagógico }\end{array}$ & 10,0 & 8,3 \\
\hline
\end{tabular}

Fonte: Elaborado pelos autoras.

Além dos encaminhamentos feitos pelas professoras, a escola também propõe algumas intervenções para auxiliar na superação das queixas escolares, no entanto as ações não estão vinculadas diretamente ao processo pedagógico. Conforme observamos na tabela 3 , a prática referida, em quase $50 \%$ das respostas, é o encaminhamento da criança para um profissional especializado.

A equipe pedagógica da escola, em muitas situações, identifica as queixas escolares, entra em contato com a família e encaminha as crianças para o processo de avaliação, geralmente, realizado por pedagogos e psicólogos da Secretaria da Educação, possibilitando, em alguns casos, um acompanhamento psicológico e/ou psiquiátrico e, se necessário, a assistência de um fonoaudiólogo. Tal prática pode levar a escola a deixar de sentir-se responsável pelo aprendizado desse aluno, voltando, em muitas situações, a lançar mão de práticas da área médica para resolver problemas pedagógicos, conforme, criticamente, afirmam Garrido e Moysés (2010).

Hoje estamos assistindo à patologização do fracasso escolar. No entendimento de Zucolloto (2007, p. 137-138), quando isso ocorre, na escola, desencadeia-se um reducionismo biológico, que consiste em:

[...] explicar a situação e o destino de indivíduos e grupos através de suas características individuais, desse modo esconde os determinantes políticos e pedagógicos do fracasso es- colar, isentando de responsabilidades o sistema social vigente e a instituição escolar. Como decorrência dessa concepção, é o indivíduo o maior responsável por sua condição de vida e destino, as circunstâncias sociais e políticas teriam influência mínima. 
Quando a escola deixa de analisar e problematizar o que está ocorrendo para que determinado aluno não aprenda, ela pode estar perdendo uma grande oportunidade de repensar suas ações e suas metodologias em direção a um trabalho coletivo que promova o aprendizado.

Tabela 3 - Encaminhamentos realizados pela escola para os estudantes identificados com queixa escolar

\begin{tabular}{l|l|l}
\hline \multicolumn{1}{c|}{ CATEGORIAS } & $\begin{array}{c}\text { Escolas de } \\
\text { Menor DEB }\end{array}$ & $\begin{array}{c}\text { Escolas de } \\
\text { Maior WEB }\end{array}$ \\
\hline $\begin{array}{l}\text { Encaminhamento do aluno para apoio pedagógico no } \\
\text { contraturno }\end{array}$ & 16,7 & 17,4 \\
\hline $\begin{array}{l}\text { Encaminhamento do aluno para atendimento } \\
\text { individualizado }\end{array}$ & 8,0 & 8,7 \\
\hline $\begin{array}{l}\text { Encaminhamento para coordenação, supervisão } \\
\text { pedagógica ou direção e conjuntamente decidem quais } \\
\text { estratégias pedagógicas utilizar. }\end{array}$ & 8,0 & 8,7 \\
\hline $\begin{array}{l}\text { Encaminhamento para a coordenação, supervisão } \\
\text { pedagógica ou direção que convoca a família. }\end{array}$ & 24,0 & 8,7 \\
\hline Encaminhamento para um profissional especializado & 40,0 & 56,5 \\
\hline Encaminhamento para o Conselho Tutelar & 4,0 & 0 \\
\hline
\end{tabular}

Fonte: Elaborado pelos autoras.

O encaminhamento para atendimento no contraturno do horário de aulas, também adotado pelas escolas $(16,7 \%$ e $17,4 \%)$, tem se constituído em uma prática rotineira nas escolas que podem oferecer esse tipo de atendimento. O grande problema que ocorre nestas práticas é que os professores que acompanham esses alunos nem sempre têm clareza das dificuldades das crianças e do que fazer para que elas superem essas dificuldades. Consideramos que o trabalho individualizado é fundamental, mas o professor tem que sistematizar a sua intervenção com vista à apropriação dos conhecimentos pelos alunos. Ele tem que utilizar, conforme afirmam Vygotsky e Luria (1996), recursos mediadores que contribuam para que o aluno desenvolva suas potencialidades.

Experiências bem-sucedidas, também, foram relatadas pelos professores, conforme se vê na tabela 4.

Nas duas escolas, em torno de $30 \%$ das respostas, as professoras relataram que procedimentos metodológicos coletivos haviam conduzido a experiências bem-sucedidas nos casos de alunos com queixas escolares. Esse é um aspecto importante de ser retomado, pois, muitas vezes, o professor sente-se solitário diante dos problemas que ocorrem em sala de aula. Se, neste artigo, estamos questionando explicações que colocam, nos alunos e pais, a culpa da não aprendizagem, não podemos deixar de refletir, também, sobre aquelas explicações que culpam o professor pelo insucesso do aluno.

Essa forma de dicotomizar os fatos e os problemas denuncia uma visão positivista, a qual como afirmam Eidt e Tuleski (2010) ao explicarem quão nefasto é o ideário neoliberal -, acaba individualizando e particularizando as explicações de problemas que extrapolam o nível individual. O que ocorre, segundo as autoras, é o deslocamento de questões sociais para o plano individual. Nessa perspectiva, entendemos que práticas coletivas na escola, envolvendo professores, pais, pedagogos e alunos são práticas exitosas e não preocupadas em culpar as vítimas de uma 
Tabela 4 - Experiências bem-sucedidas no enfrentamento das dificuldades no processo de escolarização

\begin{tabular}{l|l|l}
\hline \multicolumn{1}{c|}{ CATEGORIAS } & $\begin{array}{c}\text { Escolas de } \\
\text { Menor DEB }\end{array}$ & $\begin{array}{c}\text { Escolas de } \\
\text { Maior DEB }\end{array}$ \\
\hline $\begin{array}{l}\text { Relato de experiência com procedimentos } \\
\text { metodológicos coletivos }\end{array}$ & 27,3 & 33,3 \\
\hline $\begin{array}{l}\text { Relato de experiência com procedimentos } \\
\text { metodológicos individuais }\end{array}$ & 0,0 & 16,7 \\
\hline $\begin{array}{l}\text { Relato de experiência com atendimento de um aluno } \\
\text { específico }\end{array}$ & 45,5 & 11,1 \\
\hline $\begin{array}{l}\text { Relato de experiência de acesso à família de de } \\
\text { estudantes com queixa escolar e encaminhamento aos } \\
\text { profissionais especializados }\end{array}$ & 9,1 & 16,7 \\
\hline Não respondeu & 18,1 & 22,2 \\
\hline
\end{tabular}

Fonte: Elaborado pelos autoras.

sociedade excludente, em que os professores são excluídos das possibilidades de ter uma boa formação, os alunos são excluídos das possibilidades de aprender e os pais são excluídos de condições dignas de sobrevivência que lhes permitam acompanhar a vida escolar dos filhos.

Chama-nos a atenção o fato de $45,5 \%$ das respostas dadas pelos professores das escolas de menor IDEB relatar experiência com atendimento de um aluno específico. Parece-nos que os professores, em muitas situações, sentem-se desafiados a fazer com que o aluno aprenda.

Exemplos de superação e enfrentamento das dificuldades, por conta do trabalho com atividades diferenciadas e também pelo acompanhamento pedagógico e acompanhamento da família, podem ser encontrados nas seguintes falas:

"Tem uma menina que é especial, tem um atraso de alguns anos e ela não lia. Nesse ano ela está lendo até que fluentemente. Ela vinha duas vezes no apoio e o trabalho era feio junto com ela, dava bastante atenção, bem individual."

"Aquela criança que tinha bastante dificuldade, foi chamada a família e a família está participando, cobrando, trabalhando comigo lá em casa. Então essa criança tem melhorado."

Questionamos, nessa parte da entrevista, o porquê de cerca de $20 \%$ das professoras não terem respondido a essa questão: estariam vendo sentido - utilizando o conceito de Leontiev (1983) - para a sua profissão? Não vivenciariam situações bem-sucedidas no enfrentamento das queixas escolares? O que temos constatado, em muitos casos, é que professores estão adoecendo por não estarem conseguindo ensinar e lidar com o dia a dia da escola, como também professores que estão na sala de aula, mas abandonaram a tentativa de cumprir com o significado social da escola de socializar os conhecimentos, como afirma Saviani (2003), ou que vivenciam um processo de alienação. Leontiev (1978, p., 275) afirma: "A divisão social do trabalho tem igualmente como consequência que a atividade material e intelectual, o prazer e o trabalho, a produção e o consumo se separem e pertençam a homens diferentes. Assim, enquanto globalmente a atividade do homem se enriquece e se diversifica, a de cada indivíduo tomado à parte estreita-se e empobrece."

Falar de queixas escolares remete a pensar no uso abusivo de medicamentos, tão em voga na atualidade, conforme se pode constatar na tabela 5. Nas entrevistas, ao solicitar que as professoras identificassem os medicamentos utilizados pelos alunos, foi apresentada uma lista contendo os seguintes medicamentos: ritalina, conserta, tegretol, gardenal, antidepressivo e outros. 
Tabela 5 - Tipos de medicamentos utilizados pelos alunos

\begin{tabular}{l|l|l}
\hline \multicolumn{1}{c|}{ CATEGORIAS } & $\begin{array}{c}\text { Escolas de } \\
\text { Menor IDEB }\end{array}$ & $\begin{array}{c}\text { Escolas de } \\
\text { Maior IEB }\end{array}$ \\
\hline Ritalina & 78,6 & 82,0 \\
\hline Risperidona & 0,0 & 6,0 \\
\hline Tegretol & 0,0 & 3,0 \\
\hline Depakene & 7,1 & 0,0 \\
\hline Não soube identificar o medicamento & 14,3 & 9,0 \\
\hline
\end{tabular}

Fonte: Elaborado pelos autoras.

Os índices mostram que, nas escolas de menor IDEB e nas de maior IDEB, o medicamento mais consumido por eles é a Ritalina (78,6\% e $82,0 \%$, respectivamente) - metilfenidato que atua como estimulante do sistema nervoso central, usado, geralmente, no tratamento do TDAH. Outros medicamentos tais como risperidona - indicada no tratamento de uma ampla gama de pacientes esquizofrênicos, tegretol - medicamento antiepilético e depakene - indicado para o tratamento da epilepsia e convulsões também foram mencionados, porém em menor número. Apenas um aluno faz uso de Depakene, medicamento utilizado para epilepsia. De acordo com uma participante, além da Ritalina e do Depakene, há um aluno medicado com Tegretol.

Não investigamos como são administrados os medicamentos na escola ou mesmo se as professoras constatam melhora nos alunos com o uso desses medicamentos. No entanto, temos autores como Garrido e Moyses (2010) e Meira (2012), por exemplo, que têm questionado os efeitos da medicalização na escola que desvia o olhar de questões institucionais e sociais para uma concepção de aprendizagem centrada em fatores biológicos. Nesta mesma direção, tem o estudo desenvolvido por Suzuki (2012) que teve por objetivo investigar, segundo o ponto de vista de educadores, os efeitos do uso de medicamentos em alunos que apresentam problemas de aprendizagem e comportamento na escola. Os resultados mostraram que nem todos os participantes consideram que há melhora na aprendizagem e no comportamento do aluno após o inicio do uso da medicação, no entanto, há aqueles que observam algumas mudanças, sobretudo, em relação à capacidade de concentração. Estes também deixaram explícito que esse tipo de meIhora ocorre ao custo de que o aluno se torna apático e isolado do ambiente escolar e da relação com outros colegas de sala.

Neurologistas têm realizado diagnósticos que mais uma vez acabam colocando no aluno a culpa por não aprender. As causas orgânicas são tratadas com medicamentos, conforme vemos nas respostas dadas pelas professoras, reforçando, como afirmam Eidt e Tuleski (2010), a visão idealista, naturalizante e biologizante do psiquismo humano. Se o aluno não aprende por ter um transtorno orgânico, conforme laudos emitidos principalmente na área médica, o que se tem que fazer é cuidar do corpo, do aspecto orgânico, dicotomizando os indivíduos e isolando-os das condições materiais que produzem o fracasso escolar. "Esse tipo de tratamento é dirigido às manifestações individuais de supostas disfunções do cérebro, separadas da realidade objetiva e do contexto em que se desenvolvem." (EIDT; TULESKI, 2010, p. 124).

É perceptível que, atualmente, a medicina tem papel central na sociedade. Os médicos dizem e ninguém os contradiz, acreditando que estes profissionais são os detentores do saber. Com isso, os pais das crianças, assim como os professores, apenas seguem a receita médica e não têm uma visão crítica acerca da dificuldade da criança, responsabilizando-a assim, novamente, pelo seu insucesso. Enquanto as grandes indústrias farmacêuticas estão investindo na produção de medicamentos que podem controlar o comportamento dos indivíduos, deixa-se de questionar 
essa sociedade que não investe na apropriação da cultura, que desvaloriza o conhecimento como possibilidade de conhecer mais profundamente a realidade e, desta forma, poder transformá-la.

Tabela 6 - Tipos de distúrbios de aprendizagem identificados em sala de aula

\begin{tabular}{l|c|c}
\hline $\begin{array}{l}\text { Tipos de distúrbios } \\
\text { identificados }\end{array}$ & $\begin{array}{l}\text { Escolas de Menor IDEB } \\
\text { \% de estudantes com } \\
\text { distúrbios identificados }\end{array}$ & $\begin{array}{l}\text { Escolas de Maior IEB } \\
\text { \% de estudantes com } \\
\text { distúrbios identificados }\end{array}$ \\
\hline Hiperatividade & 0,0 & 11,0 \\
\hline TOD & 50,0 & 25,2 \\
\hline TDAH & 21,4 & 34,0 \\
\hline $\begin{array}{l}\text { TDAH associado a } \\
\text { Dislexia e discalculia }\end{array}$ & 0,0 & 2,0 \\
\hline Dislexia & 0,0 & 4,0 \\
\hline Transtorno bipolar & 0,0 & 5,0 \\
\hline $\begin{array}{l}\text { Transtorno obsessivo } \\
\text { compulsivo opositor } \\
\text { negativo }\end{array}$ & 0,0 & 2,0 \\
\hline $\begin{array}{l}\text { Transtorno obsessivo } \\
\text { compulsivo }\end{array}$ & 0,0 & 2,0 \\
\hline Epilepsia & 7,1 & 0,0 \\
\hline $\begin{array}{l}\text { Não soube informar o } \\
\text { distúrbio }\end{array}$ & 21,4 & 14,5 \\
\hline
\end{tabular}

Fonte: Elaborado pelos autoras.

Quando pesquisado acerca dos distúrbios de aprendizagem identificados em sala de aula, constatamos que o Transtorno do Déficit de Atenção com Hiperatividade (TDAH) $(21,4 \% \mathrm{em}$ escola de menor IDEB e 34,0\% em escola de maior IDEB) e o Transtorno Desafiador de Oposição - TOD (50\% em escola de menor IDEB e $25,2 \%$ em escola de maior IDEB) foram os mais citados. Segundo Meira (2012), com base em pesquisas realizadas na Psiquiatria, o TOD pode ser diagnosticado em até $60 \%$ das crianças e $40 \%$ dos adultos com TDAH. A autora discute o quanto que a patologização na educação tem contribuído para a exclusão do acesso ao conhecimento a um grande contigente de crianças pobres, ocultando a produção e reprodução das desigualdades sociais.

$\mathrm{Na}$ linha da crítica medicalização e à biologização das funções psicológicas superiores - no caso do TDAH, a atenção - temos também o posicionamento de Eidt e Tuleski (2010) que, respaldadas pelos pressupostos da Histórico-Cultural, propõem uma nova forma de pensar e entender o TDAH. As autoras questionam quais têm sido as mediações feitas para que essas crianças consigam desenvolver a atenção, tornando-a voluntária e colocando-a a serviço da apropriação do conhecimento. Vygoski e Luria (1996), ao analisarem o desenvolvimento do psiquismo da criança, mostram como ocorre a superação do biológico pela apropriação da cultura. Demonstram que a atenção vai se desenvolvendo, em um primeiro momento, dependente de uma direção externa e que, aos poucos, com a apropriação de novos conhecimentos, pela mediação dos 
outros, vai se tornando cada vez mais complexa, voluntária e autônoma. Assim, uma visão maturacionista ainda vem guiando a compreensão das dificuldades no processo de escolarização.

\section{4 | Considerações finais}

Por meio das respostas fornecidas pelas entrevistadas e da correlação com a revisão bibliográfica acerca de temas como queixa escolar e medicalização, foi possível identificar uma alta responsabilização do indivíduo por seu fracasso escolar. Explicações produzidas cerca de 50 anos atrás se perpetuam e ganham novas roupagens. Se na década de 1980, falávamos de Disfunção Cerebral Mínima e prescreviamos Gardenal para os alunos, hoje falamos, por exemplo, em TDAH e receitamos Ritalina. A medicina continua tendo influência na educação e pode direcionar, em muitas situações, para um tratamento que desconsidera as condições histórico-sociais que produzem um aluno com dificuldade para ler, escrever e contar, ou um aluno com comportamento considerado indisciplinado.

A busca do culpado continua incessante, mas não basta simplesmente culpar pais que querem que seus filhos se concentrem e aprendam, ou culpar professores que querem comportamentos disciplinados para que possam dar conta de uma sala de aula de 30, 40 alunos. Muitas vezes, a descontrolada medicalização tem sido banalizada por professores que acreditam ser o remédio a solução para o fracasso escolar. Vivemos, em muitas ocasiões, repetições de ações e explicações frente às dificuldades no processo de escolarização.

Não gostaríamos de terminar esse artigo lamentando os resultados obtidos com a pesquisa apresentada. Do nosso ponto de vista, não seria o melhor meio de enfrentar as queixas escolares. Assim, finalizamos fazendo algumas proposições que podem colaborar para o processo ensino-aprendizagem. Nos posicionamos em defesa de uma escola que trabalhe em prol do desenvolvimento máximo das potencialidades dos alunos. E, ainda, que leve em consideração a desigualdade que ocorre no acesso ao conhecimento na sociedade capitalista, quando analisa as dificuldades no processo de escolarização.

Em primeiro lugar, consideramos necessário compreender que o aluno com dificuldades no processo de escolarização vive em uma sociedade excludente, que não socializa os bens materiais e culturais de forma igualitária, ao passo que, para Vygotski (1997), o homem, desde que nasce, é um ser social. A história das relações que os homens estabelecem na sociedade, tomada como referência a base material, vai produzir esta ou aquela explicação para os fatos humanos. No caso do insucesso escolar, as causas são depositadas nos indivíduos, uma vez que o ideário neoliberal dirige as ações humanas; no entanto, tal compreensão, por si só, não auxiliará o aluno no seu processo de escolarização. Pode cercear o preconceito em relação aos alunos vindos da classe trabalhadora, mas não resolve seu problema. No espaço intraescolar cabe, então, estabelecer, sistematizar e utilizar atividades que incidam na zona de desenvolvimento proximal ou iminente - utilizando tradução de Prestes (2012) que assevera que "iminente" é o termo que melhor exprime o conceito em questão - dos alunos, ensinando, como afirma Vigotski (2000), aquilo que a criança ainda não aprendeu. Dessa forma, recursos mediadores diferenciados precisam ser utilizados pelos professores para que os alunos aprendam.

Falamos daqueles que estão à margem do ensino, mas eles, juntamente com todos os demais alunos, precisam de mediações que possibilitem a transformação da consciência para que conheçam a realidade na sua essência. Markus (1974) afirma que, ao formar os conceitos teóricos, o aluno pode obter um maior conhecimento da realidade, uma vez que novas capacidades intelectuais vão sendo formadas. "Assim, as condições sociais dos indivíduos, generalizando-se cada vez mais, permitem a cada indivíduo mostrar-se cada vez mais apto a aproveitar experiências, conhecimentos e riquezas acumulados pela humanidade" (MARKUS, 1974, p.88). 
A apropriação dos conhecimentos científicos, conforme anuncia Vigotski (2000), possibilita a complexificação das funções psicológicas superiores e a formação da consciência. No entanto, somente na coletividade as transformações sociais poderão ocorrer. Coletividade implica em um trabalho institucional, assim como maior investimento nos recursos destinados à educação, e, principalmente, políticas públicas que auxiliem na apropriação do conhecimento e na superação das dificuldades no processo de escolarização. Como afirma Vygotsky (1930), para formar um novo homem é necessário alterar as relações de trabalho no que diz respeito à valorização do trabalho braçal e intelectual. Assim como, modificar as relações entre as pessoas nos comportamentos presentes na sociedade e na escola, sobretudo, nas relações pedagógicas.

\section{5 | Agradecimentos}

Aos alunos de graduação e Pós-graduação em Psicologia, que participaram na coleta dos dados do estudo: Jordana Maria da Silveira; Maria Eduarda Pacola; Ana Paula Paz Tavares e Leandro Carmo de Souza.

Agradecemos a CAPES pelo financiamento dado a pesquisa. 


\section{Referências}

ANUÁRIO BRASILEIRO DA EDUCAÇÃO BÁSICA. Todos pela Educação. São Paulo: Ed. Moderna, 2012. Disponível em: <www.moderna.com. br\%2Flumis\%2Fportal\%2Ffile\%2FfileDownload.jsp>. Acesso em: 28 jun. 2013.

BRASIL. Ministério do Planejamento, Orçamento e Gestão. Assessoria Econômica. Indicadores de desenvolvimento brasileiro, 2013. Disponível em: <http://www.planejamento. gov.br/secretarias/upload/Arquivos/publicacao/indicadores_ de_desenvolvimento.pdf>. Acesso em: 27 jun. 2013.

DAVIDOV, V.; MÁRKOVA, A. La concepción de la actividad de estudio de los escolares. In: DAVIDOV, V; SHUARE, M. (Org.). La psicologia evolutiva y pedagógica en la URSS (Antologia). Moscou: Editorial Progresso, 1987. p. 316-36.

ELKONIN, D. Sobre el problema de la periodización del desarrollo psíquico en la infancia. In: DAVIDOV, V.; SHUARE, M. (Org.). La psicologia evolutiva y pedagógica en la URSS (Antologia). Moscou: Editorial Progresso, 1987. p. 125-142.

EIDT, N. M.; TULESKI, S. C. Transtorno de déficit de atenção/hiperatividade e psicologia históricocultural. Cadernos de Pesquisa, São Paulo, v. 40, n. 139, jan./abr. 2010. Disponível em: <http://www. scielo.br/scielo.php?script=sci_arttext\&pid=S0100 15742010000100007\&lang=pt>. Acesso em: 10 ago. 2012.

FACCI, M. G. D. Valorização ou esvaziamento do trabalho do professor? Um estudo crítico-comparativo da teoria do professor reflexivo, do construtivismo e da psicologia Vigotskiana. Campinas: Autores Associados, 2004.

"Professora, é verdade que ler e escrever é uma coisa tão fácil?": reflexões em torno do processo ensinoaprendizagem na perspectiva Vigotskiana. In: MEIRA, M. E. M; FACCI, M. G. D. (Org.). Psicologia histórico-cultural: contribuições para o encontro entre a subjetividade e a educação. São Paulo: Casa do Psicólogo. 2007, p. 135156 .

GARRIDO, J.; MOYSÉS, M. A. A. Um panorama nacional dos estudos sobre a medicalização da aprendizagem de crianças em idade escolar. In: CONSELHO REGIONALDE PSICOLOGIA DE SÃO PAULO (Org.). Medicalização de crianças e adolescentes: conflitos silenciados pela redução de questões sociais a doença de indivíduos. São Paulo: Casa do Psicólogo, 2010. p.149-162.

\section{INSTITUTO NACIONAL DE ESTUDOS E PESQUISAS} EDUCACIONAIS ANÍSIO TEIXEIRA. Censo da educação básica: 2012: resumo técnico. Brasília, DF, 2013.

LEONTIEV, A.N. O desenvolvimento do psiquismo. Lisboa: Livros Horizonte, 1978.

Actividade, consciência personalidade. Havana: Pueblo e Educación, 1983.

MARKUS, G. Teoria do conhecimento no jovem Marx. Rio de Janeiro: Paz e Terra, 1974.

MEIRA, M. E. M. Para uma crítica da medicalização na educação. Psicologia Escolar e Educacional, São Paulo, v.16, n. 1, jan./jun. 2012.
MEIRA, M. E. M. Incluir para continuar excluindo: a produção da exclusão na educação brasileira à luz da psicologia histórico-cultural. In: FACCI, M. G. D.; MEIRA, M. E. M.;

TULESKI, S. C. (Org.). A exclusão dos "incluídos": uma crítica da psicologia da educação à patologização e medicalização dos processos educativos. Maringá: Eduem, 2011. p. 91-132.

PATTO, M. H. S. A produção do fracasso escolar: histórias de submissão e rebeldia. São Paulo: T.A. Queiroz, 1990.

Psicologia e ideologia: uma introdução crítica à psicologia escolar. São Paulo: T. A. Queiroz, 1984.

PETROVSKI, A. Psicologia evolutiva y pedagógica. Moscou: Editorial Progresso, 1985.

PRESTES, Z. Quando não é quase a mesma coisa: traduções de Lev Semionovitch Vigotski no Brasil. Campinas, SP: Autores Associados, 2012.

SAVIANI, Dermeval. Pedagogia histórico-crítica: primeiras aproximações. 8. ed. Campinas: Autores Associados, 2003.

SOUZA, M. P. R. A queixa escolar na formação de psicólogos: desafios e perspectivas. In:

TANAMACHI, E. R.; ROCHA, M, L.; SOUZA, M. P. R. (Org.). Psicologia e educação: desafios teóricos-práticos. São Paulo: Casa do Psicólogo, 2000.

SUZUKI, M. A. A medicalização dos problemas de comportamento e da aprendizagem: uma prática social de controle. 2012. 174f. Dissertação (Mestrado em Psicologia) - Universidade Estadual de Maringá, Maringá-PR, 2012.

UNESCO. Relatório de monitoramento de educação para todos Brasil 2008: educação para todos em 2015; alcançaremos a meta? Brasília, DF: UNESCO, 2008.

VYGOTSKY, L.S.; LURIA, A. R. Estudos sobre a história do comportamento: símios, homem primitivo e criança. Porto Alegre: Artes Médicas, 1996.

VIGOTSKI, L. S.. Psicologia pedagógica: un curso breve. Buenos Aires: AIQUE, 2001.

A construção do pensamento e da linguagem. São Paulo: Martins Fontes, 2000.

Obras Escogidas V. Madrid: Centro de Publicaciones del M.E.C. y Visor Distribuciones, 1997.

A transformação socialista do homem. URSS: Varnitso, 1930. Disponível em: <http//:marxists.anu.edu. au/portugues/vygotsky/1930/mes/transformacao.htm>. Acesso: em 12 fev. 2014. (Tradução Marxists Internet Archive, english version, Nilson Dória, julho 2004).

ZUCOLOTO, P. C. S. V.. O médico higienista na escola: as origens históricas da medicalização do fracasso escolar. Rev. Bras. Crescimento Desenvolv. Hum., São Paulo, v. 17, n. 1, p.136-145, abr. 2007. Disponível em: <http://pepsic. bvs-psi.org.br/scielo.php?script=sci_arttext\&pid=S0104$12822007000100014 \& \mathrm{lng}=\mathrm{pt} \& \mathrm{nrm}=\mathrm{i} \& \& \mathrm{lng}=\mathrm{pt}>$. Acesso em: 5 jul. 2008.

Cad. Pes., São Luís, v. 21, n. 1, jan./abr. 2014. 